\title{
Differences in biometry and body condition of the House Sparrow (Passer domesticus) in urban and rural population during breeding season
}

\author{
Beata Dulisz $^{1}$ • Jacek J. Nowakowski ${ }^{1}$ - Joanna Górnik ${ }^{2}$
}

Published online: 29 February 2016

C) The Author(s) 2016. This article is published with open access at Springerlink.com

\begin{abstract}
Data collected out of the breeding season suggest that House sparrows (Passer domesticus) from the urban populations are characterized by a smaller body size and poorer body condition compared to birds from rural populations. Considering an urbanized Eurasian Sparrowhawk (Accipiter nisus) and other potential predators, a new predator-prey dependency is developing that can also be a reason for the House sparrow's poorer condition. This study was aimed at comparing the multivariate biometrical characteristics and few body condition indices of adult birds from urban and rural populations during the breeding season. It was hypothesized that a higher predation risk during the breeding season concerns mainly males, thus affecting their poorer condition. Most of the condition indices of males were significantly lower in the urban population. Males from the urban populations had lower body mass, shorter tarsus, longer alula, greater Kipp's distance and higher wing pointedness index in comparison to the birds from rural populations, whereas these differences were not found between females. We suggest that the lower body condition and biometric differences in the analyzed birds are a means of adapting to the new predator-prey scheme in accordance to the tradeoff theory between starvation and predation risks. A lower condition of birds in poor foraging urban habitats and higher predation risk may be indicative of a declining population.
\end{abstract}

Keywords Adaptation traits · Bird flight's adaptation - Body condition index · House Sparrow population decline $\cdot$ Morphometry $\cdot$ Natural selection $\cdot$ Urban birds

Beata Dulisz

beata.dulisz@uwm.edu.pl

1 Department of Ecology and Environmental Protection, Faculty of Biology and Biotechnology, University of Warmia and Mazury in Olsztyn, Plac Łódzki 3, 10-727 Olsztyn, Poland

2 Zoological Garden, ul. Spacerowa 10, 45-094 Opole, Poland 


\section{Introduction}

The House Sparrow, known for its occurrence within human habitats, has become a widely distributed species, reaching vast numbers in urbanized areas. Urban conditions support population growth with high amounts of easily accessible food, a milder climate, especially during winter, limited predation as well as a multitude of potential nesting sites (Marzluff 2001; Adams et al. 2005).

The previous comparative research on urban and rural populations of the House sparrow indicate that in urban areas the birds have a lower body mass, shorter tarsus and a weaker condition than in rural habitats (Liker et al. 2008; Seress et al. 2011). These differences by may explained by Shochat's credit card (Shochat 2004) assumptions that the urban exploiter species reach high population numbers, which results in a significant increase in the number of individuals with a lower body condition compared to the populations in rural areas. According to this hypothesis, natural selection, in this case, favors parents that raise large broods of weaker offspring because their chances of survival are higher in the urban environments due to the predictability of food supply and reduced mortality. In turn, a rapid population growth may lead to the overexploitation of the food base and increased competition for resources (Anderies et al. 2007). Weaker or less competitive individuals will ultimately feed less and will never be able to reach their physical potential, but in accordance with the credit card hypothesis these smaller individuals will still have a high survivability rate and constitute a large part of the population, whereas only a small group of super competitors will manage to maintain a high body condition (Anderies et al. 2007).

Until recently, the House Sparrow has been the prevailing species in the urban avifauna (Dulisz and Nowakowski 1996; Nowakowski 1996; Kelcey and Rheinwald 2005). The first notable population decline, which occurred in the 1970s throughout many cities of the UK, has initiated a successive population decline trend across Europe, especially in highly urbanized areas (Dott and Brown 2000; Prowse 2002; De Laet and Summers-Smith 2007). Thus, the credit card hypothesis does not provide an explicit elucidation of the differences found between urban and rural populations. Also, the competition for resources in large populations has not been confirmed to be the reason behind the weaker condition of the urban House sparrows, which has been proven in an experiment conducted in a mixed flock of sparrows from urban and rural areas. These birds, kept in captivity under the same conditions and under the influence of various factors, showed no differences in their ability to compete (Bókony et al. 2010).

Authors of ample works indicate many potential factors contributing to the decline of the House sparrow's population numbers (Summer-Smith 2003; Vincent 2005; Chamberlain et al. 2007; Shaw et al. 2008). One of them is the increasing predation risk associated with changes in the structure of urban biocenosis including an increase in species composition and density of predators as well as changes in their distribution across urban areas and the way they use the new environmental resources. This new situation changes the assumptions of the credit card hypothesis regarding lower mortality in urban areas, and for some species the predation risk in urban habitats becomes very high. The most significant population density increase of predators in the cities of the Northern Hemisphere concerns certain Accipitriformes such as the Eurasian Sparrowhawk (Accipiter nisus), the Northern Goshawk (Accipiter gentilis), the Common Kestrel (Falco tinunculus) and the Merlin (Falco columbarius) (Sodhi and Oliphant 1992, 1993; Salvati et al. 1999; Kübler et al. 2005; Rutz 2006; Chamberlain et al. 2009a; Bell et al. 2010), as well as some of the Corvidae (Nowakowski 1996; Nowakowski and Dulisz 
2005; Wojciechowska and Dulisz 2014). Kübler et al. (2005) confirmed high adaptability of Common Kestrels to use new food resources. Research conducted in the city's downtown area of Berlin revealed that the Common Kestrel's pellets contained mainly bird remains, most of which were the remains of House Sparrows. Besides bird predators, mammals also play an important role, as well the Domestic Cat (Felis catus) (Woods et al. 2003; Baker et al. 2008).

The impact of predators on birds can be direct, leading to the elimination of individuals from a population, or indirect, consisting in, e.g., development of new behavioral strategies in order to adjust to the new predator-prey system. In many cases, the natural selection may cause rapid directional changes in the genetic structure and phenotypic adaptation, thereby triggering far-reaching specific consequences for the natural populations and birds adaptation to the changing environment (Kingsolver et al. 2001, 2012; Nowakowski and Wojciechowski 2002; Nowakowski 2011). As a factor of selection, urbanization may also lead to evolutionary changes in population's adaptation (Rodewald and Shustack 2008; Chamberlain et al. 2009b; Rodewald et al. 2014), especially as a response of individual avian species being dependent on the local ecological mechanisms (Rodewald 2012). A new adaptive response of potential preys linked with avoidance of predation risk can lead to changes in their body size and condition (Cresswell 2008; Vangestel et al. 2010).

Lower body mass and poorer body condition is a form of adapting to meet the daily energy demand in an unfavorable environmental structure (fragmentation of habitats) with limited food resources, which also minimizes the risk of predation (Bruun and Smith 2003; Mitchell and Powell 2004). This balance between the risk of starvation and the risk of predation, observable in the varying body mass of small birds, was forged into a theory of the starvationpredation risk trade-off (Lima 1986; McNamara 1987). According to this hypothesis, the increase in body mass, associated with the ability to accumulate energy reserves, can be explained as a defense mechanism against the unpredictability of food supplies, especially during winter time when increase is observed in both starvation and predation risk in good foraging habitats (Houston and McNamara 1993; Bednekoff and Houston 1994; Thomas 2000; MacLeod et al. 2007, 2008). On the other hand, the decrease in body mass at a high predation risk is determined by a limited exposure time during feeding and enhanced flight efficiency that increases the chance of escaping a predator's assault in poor foraging habitats (Brodin 2000; Krams 2002; Kullberg et al. 2002; MacLeod et al. 2005, 2007). Therefore, bird body mass should increase while the risk of starvation rises, but it may also increase or decrease when the risk of predation rises, depending on the quality of the food environment. The body mass of birds is also associated with morphometry of the flight apparatus (wing, tail), which is a consequence of optimizing and managing flight energy expenditure. Rayner (1988) points out that wing shape may strongly determine energy expenditure and technique of flight. Selective pressure may optimize the mutual proportions of the wing and tail, affecting different aspects of force distribution during flight (Videler 2005).

Results of investigations conducted so far on the condition and body mass concern the population of the House Sparrow outside of the breeding season. There is no such research estimating differences in birds condition during the breeding season. Assuming that the body mass changes are due to a tradeoff between the risk of starvation and the risk of predation, and that morphometry associated with body mass reflects the adaptation to environmental factors, it may be hypothesized that during the breeding season in poor foraging urban environments and under an increasing predation pressure, House Sparrows will have lower mass and poorer condition compared to the rural population, especially in the case of males. Male birds, in comparison to females, seem more at risk of predation during the breeding period, mostly 
because of the role they play: mainly guarding the nest and protecting the fledglings while the female hatches eggs in the next brood. Chastel and Kersten (2002) report that during the nestling period, House Sparrow females provide, on average, three times as much brooding as males. Cleasby et al. (2010) demonstrate that differences in male and female ecology underlie various survivability rates among sexes. In many birds species, including the House Sparrow, male individuals are more exposed to attacks by predators (Hein et al. 2003). A higher death rate among male House Sparrows might be caused by their contrasting plumage, which makes them more conspicuous to predators (Rohwer and Butcher 1988) and consequently leads to playing a certain role during the breeding season.

The aim of this study was to evaluate the body size and condition of urban and rural populations of House Sparrow during the breeding season and biometrical characteristics of morphological features associated with adaptation to flight. The research was conducted with two different populations, one typically urban, the other typically rural, and both having known population trends (urban: declining, rural: stable), and at varying trends in the number of predators (urban: rapidly growing, rural: fairly stable numbers).

\section{Materials and methods}

\section{Study site}

The research was conducted in north-eastern Poland, in urban areas of the city of Olsztyn $\left(53.46^{\circ} \mathrm{N}, 20.28^{\circ} \mathrm{E}\right)$ and in a rural area of the village of Szostaki $\left(53.17^{\circ} \mathrm{N}, 22.27^{\circ} \mathrm{E}\right)$.

Olsztyn $\left(88.33 \mathrm{~km}^{2}\right.$, ca. 175,000 inhabitants $)$ is situated at an altitude of $88.0-150.8$ m.a.s.1 in an area of temperate climates with Atlantic and Baltic influences as well as lakeland climate characteristics (average annual temperature $+7.2{ }^{\circ} \mathrm{C}$; average for July $+17{ }^{\circ} \mathrm{C}$; average for January $-3.5^{\circ} \mathrm{C}$; average annual precipitation $642 \mathrm{~mm}$ ). The structure of area development of the city is dominated by built-up areas (36.3\%, including $10.1 \%$ of residential areas), farmlands $(27.2 \%)$, woodlands $(22.9 \%)$ and water areas $(9.9 \%)$. The birds were caught in residential areas (many-tiered, apartment buildings; arranged green areas with a majority of lawns with planted trees and bushes). The population of House Sparrow population has been observed to drastically decrease (by up to $90 \%$ ) in the city, especially in its central part (Dulisz and Zasitko 2008; Wegrzynowicz 2013), whereas numbers of its potential predators has been shown to increase over the years 1993-2006, including populations of Sparrowhawk and Common Kestrel (Nowakowski et al. 2006), Common Magpie (Pica pica), Hooded Crow (Corvus cornix), Common Raven (Corvus corax), and Eurasian Jay (Garrulus glandarius) (Nowakowski and Dulisz 2005; Nowakowski et al. 2006). The number of breeding pairs of the Sparrowhawk has increased from two, nesting on the outskirts of the city somewhere around the area of urban forest Las Miejski, to 12 pairs, out of which 6 nested in small afforested surfaces near residential areas. Similar to the Sparrowhawk, the Common Kestrel also increased its population from 2 to 4 breeding pairs to 17, all of which inhabited buildings of residential areas. Among the Corvids, a significant increase of population numbers was observed in the Common Magpie from approx. 300 pairs in 1993 to 490-500 pairs in 2006; in Raven from 4 pairs (1993) to 10 pairs (2006), as well as an in Jays and Hooded Crows, with a tendency to settle in the more urbanized areas of the city. In 2014, a further increase was observed in the population numbers and density of the Magpie, with a clear synurbization phenomenon (Wojciechowska and Dulisz 2014). 
The village of Szostaki (several agricultural holdings, ca. 60 inhabitants) is situated on the edge of Kolno Highland (120-123 m.a.s.l), over which runs the Biebrza River valley. Adjoined by the Biebrza National Park, it is an area of temperate climates with some continental climate influence (average annual temperature $+6.5^{\circ} \mathrm{C}$, average for July $+17{ }^{\circ} \mathrm{C}$, average for January $-4.2^{\circ} \mathrm{C}$; average annual precipitation $550 \mathrm{~mm}$ ). The village is surrounded by a predominantly open landscape with high share of alluvial and wet meadows, pastures and inconsiderable forest covers. Land development is mostly agricultural, with farm buildings, household orchards, some ornamental shrubs and lawns. Trees and the small area of wastelands are along the roads. Over the years 1989-2011, the density of Sparrows in the Szostaki village was similar in the consecutive breeding periods, and only few potential predatory species were reported in the natural habitats outside the village, nesting in a similar number of pairs (surrounding forests - 01 pair of Sparrowhawk, flooded Biebrza river valley - 3-4 pairs of Common Magpie, and 1-3 pairs of the Hooded Crows), however there was no evidence of regular visits of the potential predators on the village area in the study period.

\section{Field methods and measuring data}

The birds were caught from 2004 to 2007 as well as in 2011, from April through July, using mist nets (Japanese nylon nets). Both in rural and urban areas, the nets (1-4) in were used to capture the pairs of birds in their breeding territories, in the vicinity of nests. The study was conducted on the Sparrow populations nesting in buildings (there were no artificial nesting boxes for birds on both study areas). 96 birds were caught in the city area (50 females and 45 males) and 74 were caught in the village area ( 38 females and 36 males). The birds were individually ringed, their sex and age were determined, and body fat composition was ranked on a scale from 0 to 5 according to the Operation Baltic methods (Busse 1990). Measurements of the wing, alula, tail, tarsus length, Kipp's distance, wing formula and body mass were taken. All of the measurements were conducted following the Operation Baltic methods (Kipp 1959; Busse 1990). Linear measurements of primaries, wings and tails were conducted using a ruler accurate to $1 \mathrm{~mm}$. The length of the tarsus was measured with a MEASY 2000 caliper, accurate to $0.1 \mathrm{~mm}$. The body mass was weighed on an electronic TANITA scale, accurate to $0.1 \mathrm{~g}$.

Based on the wing's formula measurement, the Hołyński wing pointedness index (1965), adjusted by Nowakowski (2011) to include the difference between the total length of the proximal and distal remiges and the Kipp's distance and standardized to the wing length, was used to create a biometric profile of the birds. Standardization of the wing pointed index to the wing length allows for more accurate reflection of differences in wing shape and flight adaption within a population.

The following indicators were used in order to create the profile of the body condition of the birds: $\mathrm{F}$ - degree of fat score; $\mathrm{BM}$ - body mass; $\operatorname{logBM}$ - body mass logarithm; $\mathrm{BM} \mathrm{WL}^{-1}$ - body mass wing length ${ }^{-1} ; \operatorname{logBM} \operatorname{logWL}{ }^{-1}$ - body mass logarithm wing length logarithm ${ }^{-1} ; \mathrm{BM} \mathrm{TL}^{-1}$ body mass tail length ${ }^{-1}$; $\mathrm{BM} \mathrm{T}^{-1}$ - body mass tarsus length ${ }^{-1}$; and $\log \mathrm{T}-$ tarsus length logarithm.

\section{Statistical analysis}

Differences in average results of the examined biometric features and indices of bird condition, depending on the sex and population (urban or rural), were tested using models of multivariate analysis of variance (MANOVA) in a factorial design. Afterwards, all examined features and condition indices were analyzed using GLM models - Factorial Variance Analysis, whereas in 
cases of no significant interaction, the models of Nested ANOVA - Sex[Population] were applied. The significance of difference in all of the compared means between sexes and population groups was determined using a Duncan test. The relations between the examined metric features were described with correlation coefficients.

The correlations between body condition indices and metric features of House Sparrows were analyzed using a factor analysis method and the principal component analysis in the model with morphometry features as additional variables as a method of extracting the linked variables (Fergusson and Takane 1989; StatSoft 2013). This allowed distinguishing the conceptual variables that synthetically define the morphometric characteristics and condition of the birds within the examined populations. Results of the factor analysis were validated by running a Bartlett's test of sphericity (Bartlett 1954). The number of distinguished factors was based on the combined criteria by Kaiser (1958) and Cattell (1966).

The level of significance was set at $P<0.05$. Calculations were performed using STATISTICA 9.1 software.

\section{Results}

\section{Biometric features of the population}

Multivariate comparisons of bird biometrics show a strong diversity of features among males and females (MANOVA: Wilks test: $\lambda=0.570 ; F_{8,124}=11.687 ; P<0.001$ ) and among the urban and rural populations (Wilks test: $\lambda=0.679 ; F_{8,124}=7.321 ; P<0.0001$ ), with a significant difference in the direction of feature variation between males and females of both populations (interaction: sex - population: Wilks test: $\lambda=0.847 ; F_{8,124}=2.790 ; P=0.007$ ).

A significant difference was noted among males in the direction of variation in alula length, Kipp's distance and the wing pointed index, all of which were similar among females of both populations (Duncan test: $P>0.05$ ). The urban males had a significantly longer alula, higher Kipp's distance and a higher value of the wing pointed index, compared to the males from the rural population (Duncan test: $P<0.05$ ) - (Tables 1 and 2). Males of the urban population had a longer wing, tail and alula, a higher Kipp's distance and pointier wings, compared to the females of the same population. Within the rural population, males had longer wing and tail as well as a lower value of the wing to tail ratio (Tables 1 and 2). Males and females of both populations had similar tarsus length and body mass (Tables 1 and 2). But males of the urban population, compared with the rural population, had a longer alula and tail, a lower value of the wing to tail ratio, a higher Kipp's distance, more pointed wings, shorter tarsus and a significantly lower body mass (Tables 1 and 2). In turn, females of the urban population had longer wing and tail and a lower value of the wing to tail ratio. Considering the alula and tarsus length, as well as the Kipp's distance, wing shape and body mass, females of the rural population showed no difference (Tables 1 and 2). Other features, such as the variability of wing, alula and tail length, the Kipp's distance as well as the wing to tail length ratio, were lower in birds from the urban habitat compared to the rural population. The variability of these features was lower than the variability of body mass (Table 1). In a group of females, the tendency for varying plumage features between the urban and rural populations was similar, except for Kipp's distance and wing pointedness index (Table 1). This allows us to believe that some selecting factor exists which limits the morphometric variability of the birds in traits important to flight adaptation. 


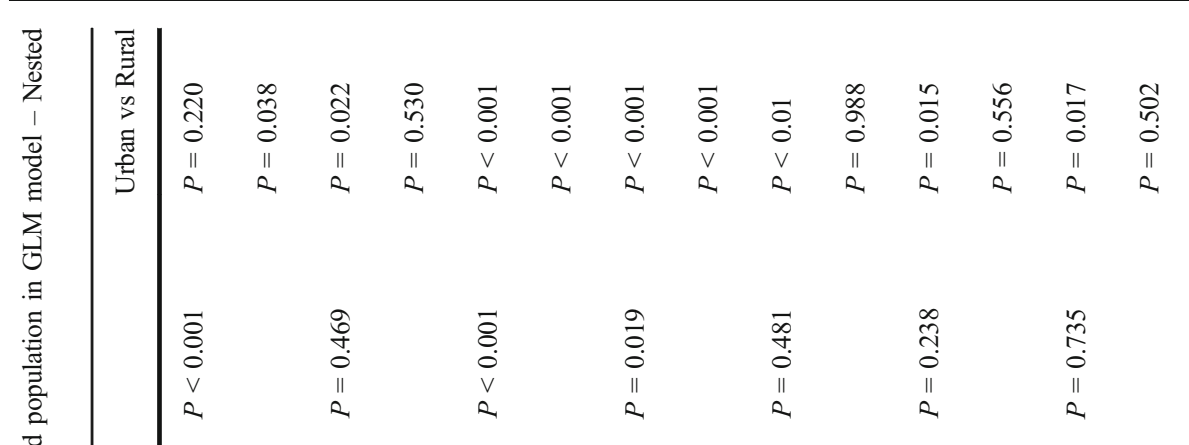

(1)

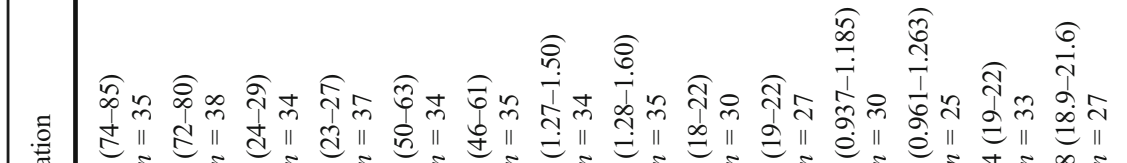

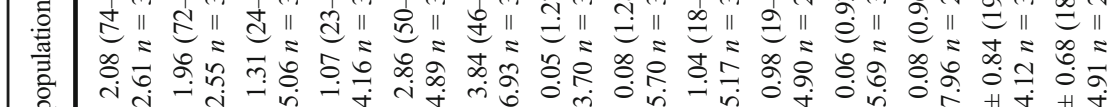

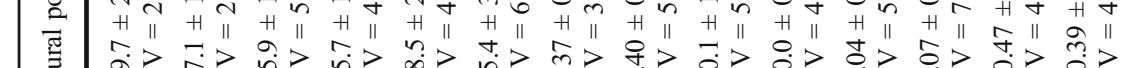

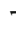

言

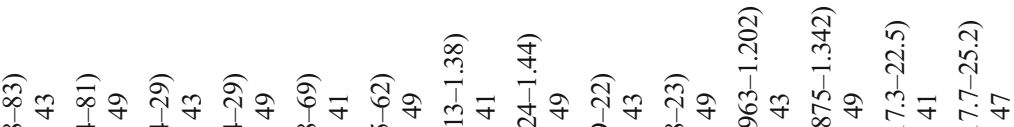

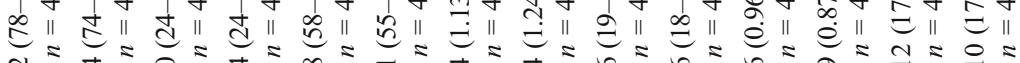

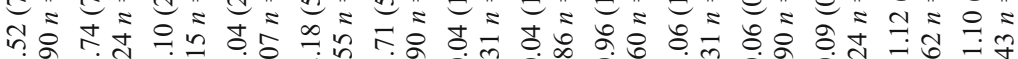

产

兽

H

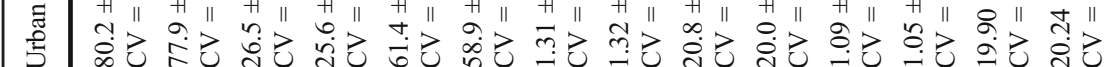

车

. 


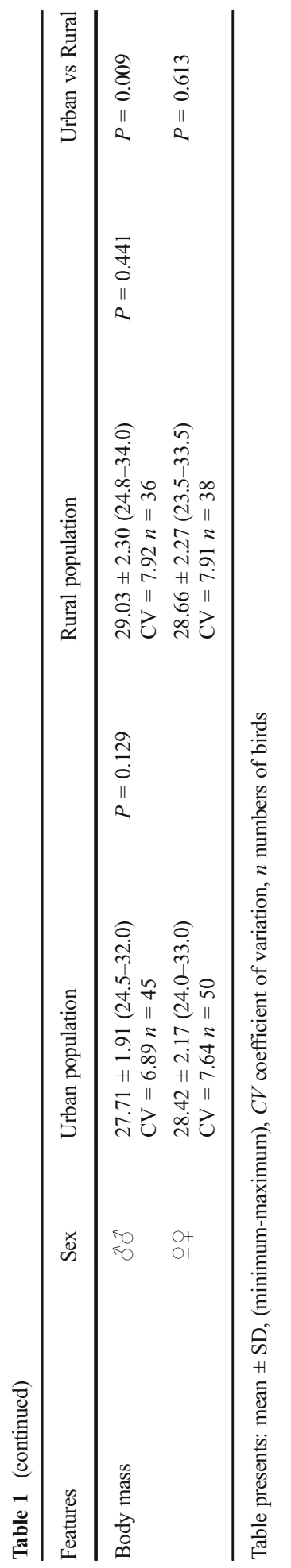




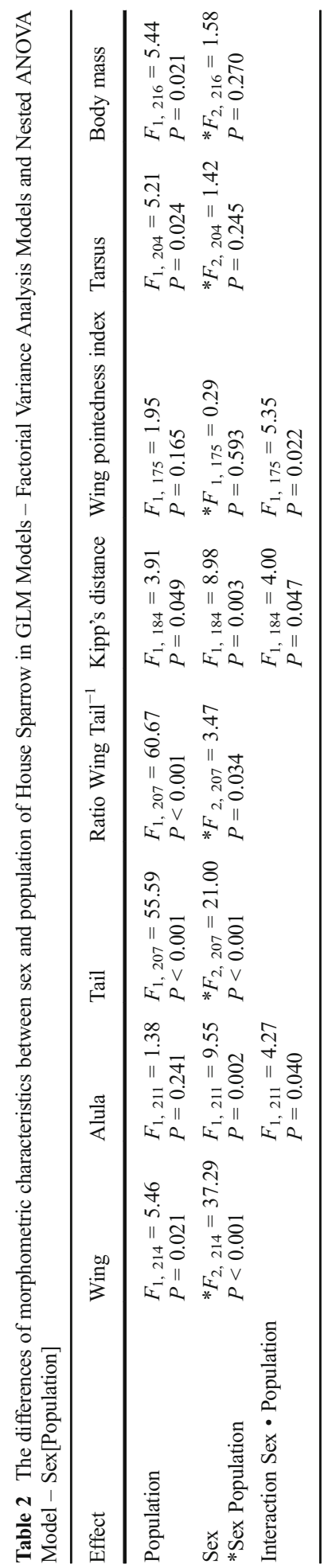


Correlation analysis suggests that within both populations, the wing length was significantly linked with the tail length (Urban: $r=0.55, n=90, P=<0.001$; Rural: $r=0.78, n=69$, $P<0.001$ ), while being only slightly relevant with the Kipp's distance (Urban: $r=0.48$, $n=92, P=0.017$; Rural: $r=0.35, n=57, P=0.008$ ), the wing pointedness index (Urban: $r=0.26, n=92, P=0.013$; Rural: $r=-0.03, n=55, P=0.846$ ), tarsus length (Urban: $r=0.25$, $n=88, P=0.017$; Rural: $r=0.32, n=68, P=0.009$ ), and body mass (Urban: $r=0.11, n=92$, $P=0.281$; Rural: $r=0.41, n=73, P<0.001$ ). The correlation coefficients of alula, tail length and wing pointedness index, Kipp's distance with the body mass and tarsus length were low and statistically insignificant, but for the body mass and tarsus length alone they reached as follows: Urban: $r=0.34, n=88, P<0.01$; Rural: $r=0.28, n=68, P=0.021$.

\section{Body condition of birds}

Significant differences were observed in body condition indices between males and females (MANOVA; Wilks test: $\lambda=0.560 ; F_{6,143}=18.698 ; P<0.001$ ) as well as between urban and rural populations (MANOVA; Wilks test: $\lambda=0.672 ; F_{6,143}=11.624 ; P<0.001$ ).

Almost all of the used indicators, except for the $\mathrm{BM} \mathrm{T}^{-1}$, were significantly different among populations and those standardized according to the wing length $\left(\mathrm{BM} \mathrm{WG}^{-1} ; \operatorname{logBM} \operatorname{logWG}{ }^{-1}\right)$ and tail length $\left(\mathrm{BM} \mathrm{TL}^{-1}\right)$ also significantly differed between males and females (Table 3). All condition indices indicated a lower body condition of males in urban habitats and no significant differences between the condition of females of both populations (Tables 3 and 4, Fig. 1). The structure of the number of males with and without a fat score resources was not random (Table 5) - the number of rural males with a fat score reserve (F: 1-2) was significantly higher, while the urban population scored lower than expected (Fisher's exact test: $P=0.044$ ). No such differences were observed in the female groups (Fisher's exact test: $P=0.825$ ).

The relationships between body condition indices and metric characteristics of the examined populations indicates a stronger relation between the body condition and the wing pointedness index, Kipp's distance, the length of alula and tarsus, than between the wing and tail length as well as the wing tail ratio ${ }^{-1}$ (Fig. 2). Only the $\mathrm{BM} \mathrm{TL}^{-1}$ index was strongly related to the wing tail ratio ${ }^{-1}$.

\section{Discussion}

So far, investigations on the condition and biometry of the adult population of the House Sparrow have been conducted outside the breeding season and were mostly based on the analysis of simple body condition indices $\left(\mathrm{BM} \mathrm{T}^{-1}\right)$ and biometric characteristics, treated only

Table 3 Differences in body condition indices between sex and populations of the House Sparrow in Nested ANOVA Models - Sex[Population]

\begin{tabular}{lllllll}
\hline Effect & $\mathrm{BM} \mathrm{T}^{-1}$ & $\mathrm{BM} \mathrm{TL}^{-1}$ & $\mathrm{BM} \mathrm{WG}^{-1}$ & $\begin{array}{l}\operatorname{logBM} \\
\log \mathrm{WG}^{-1}\end{array}$ & $\operatorname{logBM}$ & $\log$ \\
\hline Population & $F_{1,201}=0.42$ & $F_{1,204}=39.14$ & $F_{1,211}=9.17$ & $F_{1,211}=8.03$ & $F_{1,216}=5.26$ & $F_{1,204}=5.73$ \\
& $P=0.520$ & $P<0.001$ & $P=0.003$ & $P=0.005$ & $P=0.023$ & $P=0.018$ \\
Sex[Population] & $F_{1,201}=0.53$ & $F_{2,204}=9.00$ & $F_{2,211}=7.71$ & $F_{2,211}=5.60$ & $F_{2,216}=1.55$ & $F_{2,204}=1.47$ \\
& $P=0.592$ & $P<0.001$ & $P<0.001$ & $P=0.004$ & $P=0.216$ & $P=0.233$ \\
\hline
\end{tabular}


Table 4 Body condition indices of males and females of the House Sparrow populations with the Duncan probability test of the differences between sex and populations

\begin{tabular}{|c|c|c|c|c|c|c|}
\hline Condition Index & Sex & Urban & & Rural & & $\begin{array}{l}\text { Urban vs } \\
\text { Rural }\end{array}$ \\
\hline \multirow[t]{2}{*}{$\mathrm{BM} \mathrm{T}^{-1}$} & $\hat{\partial} \sigma^{\lambda}$ & $1.392 \pm 0.107(n=41)$ & $P=0.481$ & $1.420 \pm 0.107(n=33)$ & $P=0.532$ & $P=0.293$ \\
\hline & 우우 & $1.410 \pm 0.102(n=47)$ & & $1.404 \pm 0.102(n=35)$ & & $P=0.798$ \\
\hline \multirow[t]{2}{*}{$\mathrm{BM} \mathrm{TL} \mathrm{L}^{-1}$} & $\hat{\partial} \hat{\partial}$ & $0.452 \pm 0.035(n=41)$ & $P<0.001$ & $0.498 \pm 0.035(n=34)$ & $P=0.025$ & $P<0.001$ \\
\hline & 우우 & $0.483 \pm 0.040(n=49)$ & & $0.518 \pm 0.040(n=35)$ & & $P<0.001$ \\
\hline \multirow[t]{2}{*}{$\mathrm{BM} \mathrm{WG}^{-1}$} & $\hat{\partial} \widehat{\partial}$ & $0.345 \pm 0.024(n=43)$ & $P<0.001$ & $0.363 \pm 0.024(n=35)$ & $P=0.161$ & $P=0.002$ \\
\hline & 우우 & $0.365 \pm 0.026(n=49)$ & & $0.372 \pm 0.026(n=38)$ & & $P=0.245$ \\
\hline \multirow[t]{2}{*}{$\log \mathrm{BM} \log \mathrm{WG}^{-1}$} & $\hat{\partial} \delta$ & $0.757 \pm 0.016(n=43)$ & $P=0.002$ & $0.768 \pm 0.016(n=35)$ & $P=0.329$ & $P=0.003$ \\
\hline & 우우 & $0.768 \pm 0.016(n=49)$ & & $0.772 \pm 0.016(n=38)$ & & $P=0.361$ \\
\hline \multirow[t]{2}{*}{$\log B M$} & $\partial \pi$ & $3.319 \pm 0.068(n=45)$ & $P=0.133$ & $3.365 \pm 0.068(n=36)$ & $P=0.444$ & $P=0.010$ \\
\hline & 우우 & $3.344 \pm 0.076(n=50)$ & & $3.352 \pm 0.076(n=38)$ & & $P=0.625$ \\
\hline \multirow[t]{2}{*}{$\log \mathrm{T}$} & $\widehat{\partial} \widehat{\partial}$ & $2.989 \pm 0.056(n=41)$ & $P=0.114$ & $3.018 \pm 0.056(n=33)$ & $P=0.756$ & $P=0.014$ \\
\hline & 우우 & $3.006 \pm 0.053(n=47)$ & & $3.015 \pm 0.053(n=35)$ & & $P=0.455$ \\
\hline
\end{tabular}

as variables of the body size (body mass, tarsus length). Data collected during this research provide condition characteristics based, in accordance with the suggestion by Labocha and Hayes (2012), on several morphometric indices and a multivariate biometric characteristics of the urban and rural populations of the House Sparrow during the breeding season. Several biometric and body condition traits significantly differentiate the urban and rural populations. Most of the body condition indices ( $\mathrm{F}$ - body fat cover, $\mathrm{BM} \mathrm{TL}{ }^{-1}, \mathrm{BM} \mathrm{WG}^{-1}, \operatorname{logBM}$ $\left.\log \mathrm{WG}^{-1}, \log \mathrm{BM}, \log \mathrm{T}\right)$, were significantly lower in urban populations compared to the rural populations, but the differences between males were far more distinct than between females. The body condition indices based on the body mass standardization to the length of the wing and tail $\left(\mathrm{BM} \mathrm{WG}^{-1}, \mathrm{BM} \mathrm{TL}^{-1}\right)$ were lower in males in urban population, compared to females. The body mass and tarsus length did not differ between males and females of both populations, but males from urban populations had significantly lower body mass and shorter tarsus than their rural counterparts. This is partially consistent with literature data. For example, a decreased condition of the House Sparrows occupying urban and suburban territories was confirmed by ptilochronological data from Ghent, Belgium, compared to birds from rural areas (Vangestel et al. 2010). Also Liker et al. (2008) released data, obtained out of the breeding season and in a urbanization gradient, from the city center to rural areas in Hungary, that confirm the increase of adult bird condition, body mass and tarsus length but with no significant differences between sexes.

Using a multidimensional approach, significant differences was observed in biometry between males and females of both populations. Male urban populations had a longer alula, greater Kipp's distance and a higher wing pointed index, compared to males of rural populations, whereas the female populations did not differ. This indicates the possibility of a varied adaptation to the flight characteristics, by both populations. According to Witter and Cuthill (1993) and Gosler et al. (1995), the intensification of selection pressure on body weight may be strong, because heavy individuals have limited agility and speed to escape predation. Despite no evidence for predators impact on the directional phenotypic selection of House Sparrow, we suppose that the impact of predators may explain the differences in males morphology. Also, the little variability of the wing, alula and tail lengths, Kipp's distance 

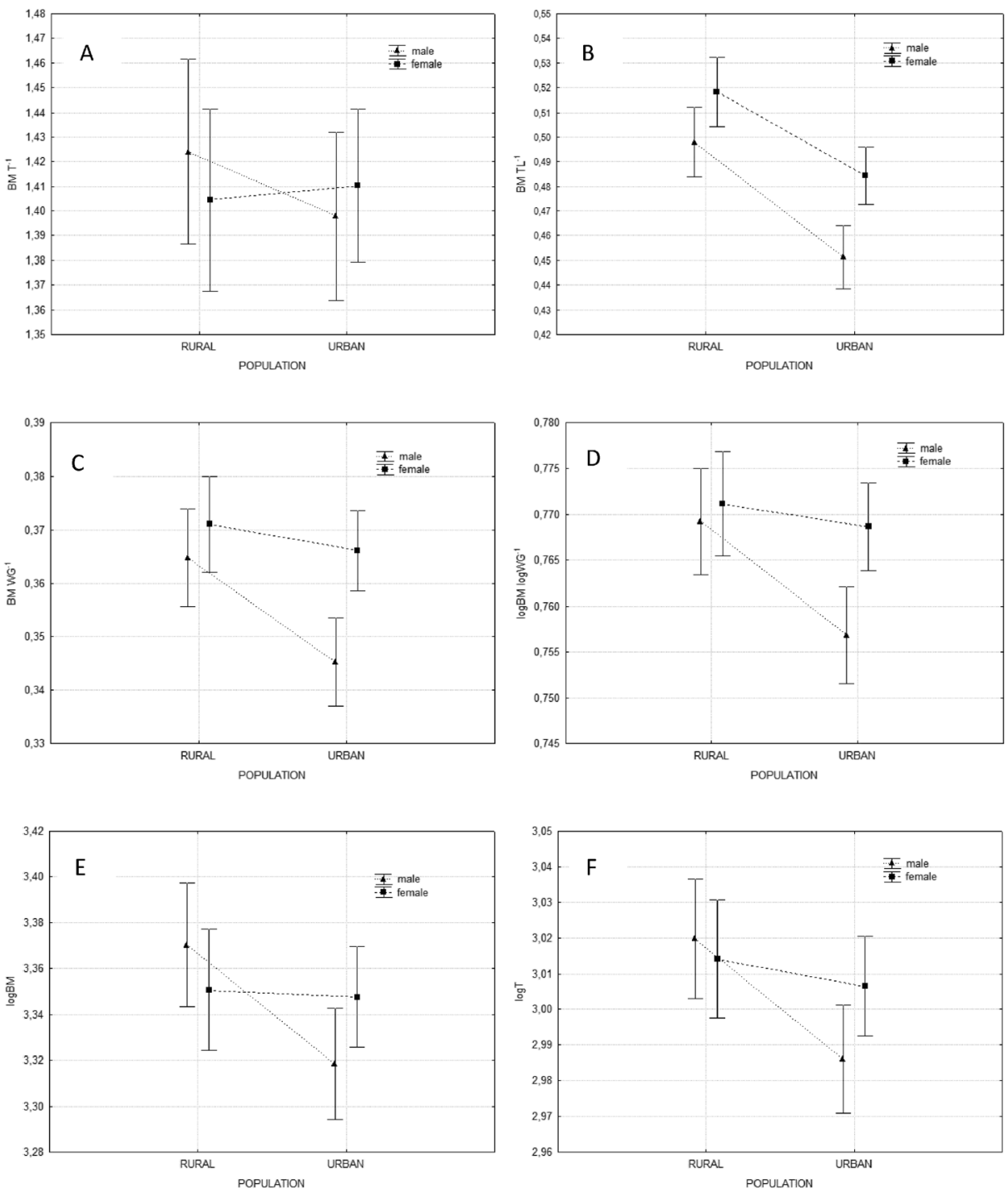

Fig. 1 Differences in body condition indices in the populations of House Sparrow

Table 5 Numbers of birds with a fat score reserve (fat score degree F: 1-2) and without (fat score degree F: 0) in urban and rural populations of House Sparrow

\begin{tabular}{|c|c|c|c|c|c|c|}
\hline \multirow[t]{2}{*}{ Fat score degree } & \multicolumn{3}{|c|}{ Urban } & \multicolumn{3}{|c|}{ Rural } \\
\hline & $\hat{\partial} \hat{O}$ & 우우 & Total & के & 우우 & Total \\
\hline F: 0 & 27 & 22 & 49 & 13 & 17 & 30 \\
\hline F: $1-2$ & 18 & 28 & 46 & 23 & 21 & 44 \\
\hline
\end{tabular}


Fig. 2 Relationships between body condition indices and morphometric characteristics of the populations of House Sparrow

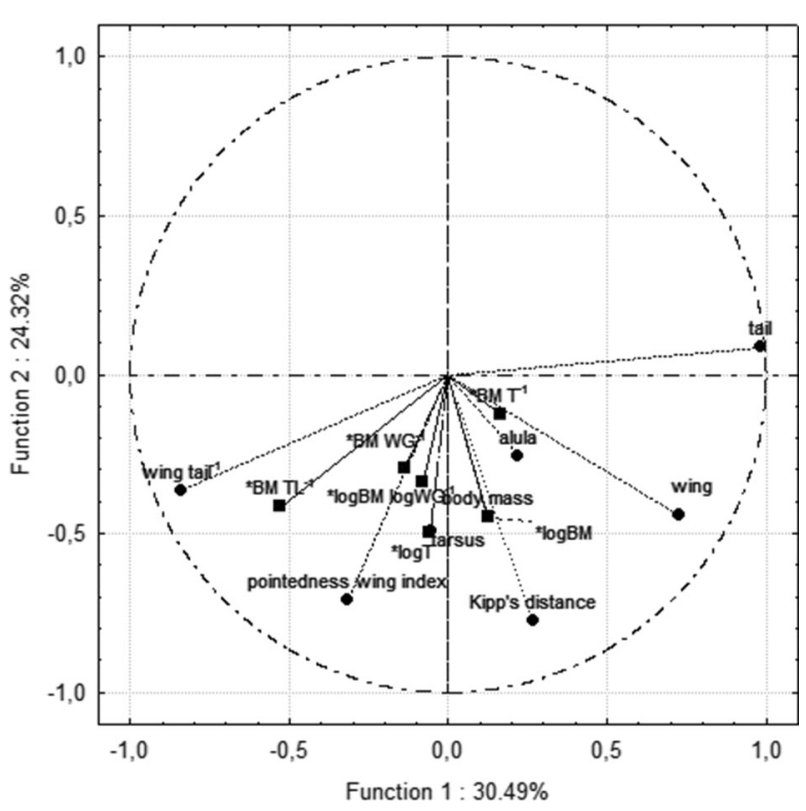

and the ratio of wing/tail length among males of urban habitats, in comparison to their rural counterparts, could be indicative of some selecting factor that reduces the morphometric variability of urban males, which is consistent with the overall objectives of selection (Futuyma 2005; Bell 2008).

Different body condition among birds of urban and suburban areas is explained in part by the Shochat's credit card hypothesis (2004). Liker et al. (2008) suggest completing the credit card hypothesis by recognizing the influence of environmental impact on the development of hatchlings or even acknowledging it as a new alternative when explaining the weaker body condition of urban birds. Numerous studies confirm the lack of food typically found in the House sparrow's diet as a result of decreasing vegetation areas throughout cities accompanied by a plant management (Robinson et al. 2005; Anderson 2006), habitat fragmentation (Vangestel et al. 2010) and an increasing share of alien plant species (Marzluff 2001; Donnelly and Marzluff 2006). In addition, increasing levels of environmental pollutants, e.g. petrol derivatives (Achten et al. 2001), have resulted in a reduction of invertebrate numbers, especially aphids, being an important source of lysine which is an indispensable amino acid for the growth and feather development in nestlings (Ricklefs 1983; Mitschke et al. 1999). Environmental conditions affect not only the nestling survival rate but also the survival rate of fledglings until they reach recruitment. These survival rates are often positively correlated with body sizes (Grant and Grant 1989; Magrath 1991; Schwagmeyer and Mock 2008).

However, the assumptions of the credit card hypothesis completed with environmental constraints, as suggested by Liker et al. (2008), do not explain why only males from the analyzed urban population had a significantly lower body mass, poorer body condition and a smaller tarsus.

The lack of differences in tarsus length between the females of both populations, being the most significant indicator of the abnormal or limited development (Anderson 2006), points to some differentiating factor other than the nutritional conditions during the nesting period. Any form of selection among nestlings, that favors the development of one sex is highly unlikely. In our opinion, 
such a diversity could possibly be formed in the post-fledging period as a result of different survivability rates of various morphometric individuals Considering the growing density of potential predators in urban habitats, the predation risk combined with the starvation risk (reducing the feeding time to avoid predation or increasing the efficiency of the flight) becomes an important cause of lower body mass and condition among urban House Sparrows, most noticeable in males during the breeding season. Vangestel et al. (2010) showed that the fragmentation of urban habitats reduced foraging areas, which were smaller than the rural ones. Urban House Sparrows tend to fly greater distances and form smaller flocks while moving between their crucial habitats (hedgerows and bush clusters), which increases the risk of predation. Their nutritional condition, assessed by the growth bars in bird feathers during feather growth, was lower than among their rural counterparts, which was described as nutritional stress.

Differing predation pressure, relative to sex, could explain the demonstrated differences in morphometry between males of the urban and rural habitats, especially that the body condition indices are related to flight adaptation traits such as wing length, Kipp's distance and the wing pointedness index. The effect of a key predator - Eurasian Sparrowhawk on selection of fledging mass was observed in the Great Tit but not in Blue Tit (Cyanistes caeruleus) (Vedder et al. 2014). We suppose that these results may indicate that in certain environmental conditions the selective pressure of a predator may vary not only in relation to different species, but probably also to different individuals, e.g. males and females. A longer alula, as seen among the urban House Sparrow population in this research, enables a quicker start, sudden stopping and better maneuverability of flight, which enables urban males to be better adapted to traveling through environments dense with spatial elements (bushes, buildings, and other anthropomorphic structures) and with little free spaces. A more pointed wing (higher wing pointedness index and Kipp's distance) optimizes energy expenditures and suggests that individuals with such a wing shape could be better prepared to flee predators, such as the Eurasian Sparrowhawk or the Common Kestrel. A similar wing shape observed among juvenile birds can also help with better energy expenditure. Juvenile individuals have a shorter wing but longer primaries, which is a form of adaptation enhancing the ability to maneuver midair at the cost of speed (Alatalo et al. 1984). Nowakowski (2011) concluded that juvenile Sedge warblers (Acrocephalus schoenobaenus) also have longer alula but also a higher wing pointedness index and bigger wing tail length ratio ${ }^{-1}$, which he interprets as a more complex flight adaptation than simple differences in the palmar wing construction mentioned by Alatalo et al. (1984). Similar differences in the morphometry of birds refers to House Sparrow males from both urban and rural habitats, which may be explained as the effect of various selective pressure of predators.

The selection could have been oriented at biometric traits associated with optimization of high flight maneuverability and adapted for easier escapes. But, this would mean simultaneous favoring of individuals with lower body mass and the ability to use the driving force of their wings more effectively, which could result in lower values of the body condition indices, especially those standardized to the length of wing and tail $\left(\mathrm{BM} \mathrm{WG}^{-1}, \operatorname{logBM} \operatorname{logWG}{ }^{-1}, \mathrm{BM} \mathrm{TL}^{-1}\right)$.

It seems as if the theory of starvation-predation risk tradeoff, combined with the credit card hypothesis, supports the explanation of why urban populations are characterized by lower body mass and lower values of the body condition indices, especially among the sex being most vulnerable to predation. Seress et al. (2011) have shown that the urban House Sparrow's response to simulated predatory attacks was far stronger than in the rural population (longer feeding interruption). Furthermore, older individuals proved to act in a more cautious way which can be explained by experience in avoiding predation risks. Experimental research on the House Sparrow's ability to flee from predators has indicated that individuals with a longer tail were caught during the 
first attempt to flee, whereas older individuals and those with larger wing lengths were only caught after multiple attempts. This might suggest a pressure for selecting birds with greater wing length and shorter tails (Moreno-Rueda 2003). Other studies have confirmed that the longer tail length of Barn Swallow males (Hirundo rustica) was correlated with a higher rate of successful attacks by Eurasian Sparrowhawk (Møller and Nielsen 1997) and that Common Starlings (Sturnus vulgaris) with higher body mass were less reflexive and, therefore, easier to catch during a chase by a predator (Witter et al. 1994). The House Sparrow's strong reaction to predatory pressure has been proven in studies by MacLeod et al. (2006, 2007). The body mass analysis of six species of passerines, caught outside of the breeding season around the UK and Ireland, indicated that no significant body increase in the winter time was only observed in the House Sparrow and that this was birds' response to predation risk instead of starvation risk. The study proved the House Sparrow's physiological ability of changing mass gain pattern by comparing the average residual mass of the House Sparrows from areas without resident Eurasian Sparrowhawks with the average residual mass of House Sparrows from areas with Eurasian Sparrowhawks present. Assuming that at the increasing starvation risk during the winter time, all of the birds that feed during the day increase their energy reserves in order to survive the long winter nights and low temperatures without depending on a supply of food (Bednekoff and Houston 1994), then no significant rise in the House Sparrow's body mass indicates a higher risk of predation when compared to other sparrow species (MacLeod et al. 2006, 2007).

In addition, MacLeod et al. (2007) proved that body mass changes as a response to predation and starvation risks, are linked with the status of the population (body mass reduction was observed in the declining population, while body mass increase was observed in the increasing populations). The authors also indicated the type of responses to predation risk depending on the quality of foraging environments. Specifically, an interrupted foraging response was shown by individuals in high quality environments, which likely increases their survival rate, while a mass-dependent foraging response (reduced body mass at the cost of decreased reserves) was shown by individuals in poor quality environments, which relatively decreases their survival rate. This latter response may concern also the urban populations of House Sparrow.

We suggest that the theory of starvation-predation risk tradeoff explains the differences in body mass, body condition and biometrics of the sex most exposed to predation risk and indicates the predator-prey relationship to be one of the potential causes of the House Sparrow's population decrease around urban habitats, which however needs further research.

Acknowledgments Field work was performed by permission of the General Environmental Protection Directorate in Poland.

Authors express their sincere thanks to Mr. Kamil Malon and Mr. Tomasz Jędra for their help with the field work.

Open Access This article is distributed under the terms of the Creative Commons Attribution 4.0 International License (http://creativecommons.org/licenses/by/4.0/), which permits unrestricted use, distribution, and reproduction in any medium, provided you give appropriate credit to the original author(s) and the source, provide a link to the Creative Commons license, and indicate if changes were made.

\section{References}

Achten C, Kolb A, Püttman W (2001) Methyl tert-butyl ethet (MTBE) in urban and rural precipitation in Germany. Atmos Environ 35:6337-6345

Adams LW, VaDruff LW, Luniak M (2005) Managing urban habitats and wildlife. In: Braun CE (ed) Techniques for wildlife investigations and management, 6th edn. The Wildlife Society, Bethesda, Maryland, pp. 714-739 
Alatalo RV, Gustaffson L, Lundberg A (1984) Why the young passerine have shorter wings than older birds? Ibis 126:410-415. doi:10.1111/j.1474-919X.1984.tb00264.X

Anderies JM, Madhusudan K, Shochat E (2007) Living in the city: resource availability, predation, and bird population dynamics in urban areas. J Theor Biol 247:36-49. doi:10.1016/j.jtbi.2007.01.030

Anderson TR (2006) Biology of the ubiquitous House Sparrow. Oxford University Press, Oxford

Baker PJ, Molony SE, Stone E, Cuthill IC, Harris S (2008) Cats about town: is predation by free-ranging pet cats Felis catus likely to affect urban bird populations? Ibis 150(Supplement s1):86-99. doi:10.1111/j.1474919X.2008.00836.x

Bartlett MS (1954) A note on the multiplying factors for various chi square approximations. J R Stat Soc 16(Ser B):296-298

Bednekoff PA, Houston AI (1994) Optimizing fat reserves over the entire winter: a dynamic model. Oikos 71: $408-415$

Bell G (2008) Selection. The mechanism of evolution, 2nd edn. Oxford University Press, New York

Bell CP, Sam WB, Parkes NG, Brooke MDL, Chamberlain D (2010) The role of the Eurasian sparrowhawk (Accipiter nisus) in the decline of the house sparrow (Passer domesticus) in Britain. Auk 127:411-420. doi: 10.1525/auk.2009.09108

Bókony V, Kulcsár A, Liker A (2010) Does urbanization select for weak competitors in house sparrows? Oikos 119:437-444. doi:10.1111/j.1600-0706.2009.17848.x

Brodin A (2000) Why do hoarding birds gain fat in winter in the wrong way? suggestions from a dynamic model. Behav Ecol 11:27-39. doi:10.1093/beheco/11.1.27

Bruun M, Smith HG (2003) Landscape composition affects habitat use and foraging flight distances in breeding European Starlings. Biol Conserv 114:179-187. doi:10.1016/S0006-3207(03)00021-1

Busse P (1990) The key to determining the age and gender of European passerine birds. Not Ornithol 31:5-368

Cattell RB (1966) The scree test for the number of factors. Multivar Behav Res 1:245-276

Chamberlain DE, Toms MP, Cleary-McHarg R, Banks AN (2007) House sparrow (Passer domesticus) habitat use in urbanized landscapes. J Ornithol 148:453-462. doi:10.1007/s10336-007-0165-x

Chamberlain DE, Glue DE, Tomps MP (2009a) Sparrowhawk Accipiter nisus presence and winter bird abundance. J Ornithol 150:247-254. doi:10.1007/s10336-008-0344-4

Chamberlain DE, Cannon AR, Toms MP, Leech DI, Hatchwell BJ, Gaston KJ (2009b) Avian productivity in urban landscapes: a review and meta-analysis. Ibis 151:1-18

Chastel O, Kersten M (2002) Brood size and body condition in the House Sparrow Passer domesticus: the influence of brooding behavior. Ibis 144:284-292. doi:10.1046/j.1474-919X.2002.00062.x

Cleasby IR, Nakagawa S, Gillespie DOS, Burke T (2010) The influence of sex and body size on nestling survival and recruitment in the house sparrow. Biol J Linn Soc 101:680-688. doi:10.1111/j.1095-8312.2010.01515.x

Cresswell W (2008) Non-lethal effects of predation in birds. Ibis 150:3-17. doi:10.1111/j.1474-919X.2007.00793.x

De Laet J, Summers-Smith JD (2007) The status of the urban house sparrow Passer domesticus in north-western Europe: a review. J Ornithol 148(suppl 2):275-278. doi:10.1007/s10336-007-0154-0

Donnelly R, Marzluff JM (2006) Relative importance of habitat quantity, structure and spatial pattern to birds in urbanizing environments. Urban Ecosyst 9:99-117. doi:10.1007/s11252-006-7904-2

Dott HEM, Brown AW (2000) A major decline in House Sparrows in central Edinburgh. Scott Birds 21:61-68

Dulisz B, Nowakowski JJ (1996) The species diversity of the avifauna in built-up areas in the city of Olsztyn (NE Poland). Acta Ornithol 31:33-38

Dulisz B, Zasitko E (2008) Changes in distribution of House Sparrow Passer domesticus in different types of building up in 1993-2007 under the impact of modernization of buildings. In: Indykiewicz P, Jerzak L, Barczak T (eds) Urban Fauna. SAR Pomorze, Bydgoszcz

Fergusson GA, Takane Y (1989) Statistical analysis in psychology and education, 6th edn. McGrow Hill, New York

Futuyma DJ (2005) Evolution, 1st edn. Sinauer Associates, Sunderland

Gosler AG, Greenwood JJD, Perrins C (1995) Predation risk and the cost of being fat. Nature 377:621-623

Grant BR, Grant PR (1989) Evolutionary dynamics of a natural population: the large cactus finch of the Galápagos. Chicago University Press, Chicago

Hein WK, Westneat DF, Poston JP (2003) Sex of opponent influences response to a potential status signal in house sparrows. Anim Behav 65:1211-1221. doi:10.1006/anbe.2003.2132

Hołyński R (1965) The methods of analysis of wing-formula variability. Not Ornithol 6:21-25

Houston AI, McNamara JM (1993) A theoretical investigation of the fat reserves and the mortality levels of small birds in winter. Ornis Scand 24:205-219. doi:10.2307/3676736

Kaiser HF (1958) The varimax criterion for analytic rotation in factor analysis. Psychometrica 23:158-163

Kelcey JG, Rheinwald G (2005) Birds in European Cities. Ginster Verlag, Katharinen

Kingsolver JG, Hoekstra HE, Hoekstra JM, Berrigan D, Vignieri SN, Hill CE, Hoang A, Gibert P, Beerlie P (2001) The strength of phenotypic selection in natural populations. Am Nat 157:245-261 
Kingsolver JG, Diamond SE, Siepielski AM, Carlson SM (2012) Synthetic analyses of phenotypic selection in natural populations: lessons, limitations and future directions. Evol Ecol 26:1101-1118

Kipp FA (1959) Der Handflügel-Index als Flugbiologisches Maß. Vogelwarte 20:77-86

Krams I (2002) Mass-dependent take-off ability in wintering great tits (Parus major): comparison of top-ranked adult males and subordinate juvenile females. Behav Ecol Sociobiol 51:345-349. doi:10.1007/s00265-0020452-8

Kübler S, Kupko S, Zeller U (2005) The kestrel (Falco tinnunculus L.) in Berlin: investigation of breeding biology and feeding ecology. J Ornithol 146:271-278. doi:10.1007/s10336-005-0089-2

Kullberg C, Metcalfe NB, Houston DC (2002) Impaired flight ability during incubation in the Pied Flycatcher. J Avian Biol 33:179-183. doi:10.1034/j.1600-048X.2002.330209.x

Labocha MK, Hayes JP (2012) Morphometric indices of body condition in birds: a review. J Ornithol 153:1-22. doi:10.1007/s10336-011-0706-1

Liker A, Papp Z, Bókony V, Lendvai ÁZ (2008) Lean birds in the city: body size and condition of house sparrows along the urbanization gradient. J Anim Ecol 77:789-795. doi:10.1111/j.1365-2656.2008.01402.x

Lima SL (1986) Predation risk and unpredictable feeding conditions - determinants of body-mass in birds. Ecology 67:377-385. doi:10.2307/1938580

MacLeod R, Barnett P, Clark JA, Cresswell W (2005) Body mass change strategies in blackbirds Turdus merula: the starvation-predation risk trade-off. J Anim Ecol 74:292-302. doi:10.1111/j. 1365-2656.2005.00923.x

MacLeod R, Barnett P, Clark J, Cresswell W (2006) Mass-dependent predation risk as a mechanism for house sparrow declines? Biol Lett 2:43-46. doi:10.1098/rsbl.2005.0421

MacLeod R, Lind J, Clark J, Cresswell W (2007) Mass regulation in response to predation risk can indicate population declines. Ecol Lett 10:945-955. doi:10.1111/j.1461-0248.2007.01088.x

MacLeod R, Clark J, Cresswell W (2008) The starvation-predation risk trade-off, body mass and population status in the common starling Sturnus vulgaris. Ibis 150(Supplement s1):199-208. doi:10.1111/j.1474919X.2008.00820

Magrath RD (1991) Nestling weight and juvenile survival in the blackbird, Turdus merula. J Anim Ecol 60:335351

Marzluff JM (2001) Worldwide urbanization and its effects on birds. In: Marzluff JM, Bowman R, Donnelly R (eds) Avian ecology and conservation in an urbanizing world. Kluwer Academic Publishers, Norwell, pp. $19-48$

McNamara JM (1987) Starvation and predation as factors limiting population size. Ecology 68:1515-1519. doi: $10.2307 / 1939235$

Mitchell MS, Powell RA (2004) A mechanistic home range model for optimal use of spatially distributed resources. Ecol Model 177:209-232. doi:10.1016/j.ecolmodel.2004.01.015

Mitschke A, Rathjen H, Baumung S (1999) House Sparrows in Hamburg: population, habitat selection and conservation status. State Centre for Bird Conservation, Hamburg

Møller AP, Nielsen JT (1997) Differential predation cost of a secondary sexual character: sparrowhawk predation on barn swallows. Anim Behav 54:1545-1551. doi:10.1006/anbe.1997.9998

Moreno-Rueda G (2003) The capacity to escape from predators in Passer domesticus: an experimental study. J Ornithol 144:438-444. doi:10.1007/BF02465506

Nowakowski JJ (1996) Changes in the breeding avifauna of Olsztyn (NE Poland) in the years 1968-1993. Acta Ornithol 31:39-44

Nowakowski JJ (2011) Long-term variability of phenotypic traits in the sedge warbler (Acrocephalus schoenobaenus) population in the Biebrza marshes -adaptation to the changing environment. Dissertation and Monographs 168. University of Warmia and Mazury in Olsztyn

Nowakowski JJ, Dulisz B (2005) Population densities and synurbization of corvids in Olszyn city (NE Poland). In: Jerzak L, Kavanagh BP, Tryjanowski P (eds) Corvids of Poland. Bogucki Wyd Nauk, Poznań, pp. 481500

Nowakowski JJ, Wojciechowski Z (2002) What determines the long-term variability in wing length in population of the Swallow Hirundo rustica and the Reed Warbler Acrocephalus scirpaceus? Ecol Quest 2:79-87

Nowakowski JJ, Dulisz B, Lewandowski K (2006) Birds of Olsztyn city. ElSet, Olsztyn

Prowse A (2002) The urban decline of the House Sparrow. Br Birds 95:143-146

Rayner JMV (1988) Form and function in avian flight. In: Johnston RF (ed) Current ornthology, vol 5. Plenum Press, New York and London

Ricklefs RE (1983) Avian postnatal development. In: Farner DS, King JR, Parkers KC (eds) Avian biology, vol 7. Academic Press, New York, pp. 1-83

Robinson RA, Siriwardena GM, Crick HQP (2005) Size and trends of the House Sparrow Passer domesticus population in Great Britain. Ibis 147:552-562. doi:10.1111/j.1474-919x.2005.00427.x 
Rodewald AD (2012) Evaluating factors that guide avian community response to urbanization. In: Lepczyk CA, Warren PS (eds) Urban bird ecology and conservation, studies in avian biology No. 45. University of California Press, Oakland, pp. 71-92

Rodewald AD, Shustack DP (2008) Urban flight: understanding individual and population-level responses of Nearctic-Neotropical migratory birds to urbanization. J Anim Ecol 77:83-91

Rodewald AD, Rohr RP, Fortuna MA, Bascompte J (2014) Community-level demographic consequences of urbanization: an ecological network approach. J Anim Ecol 83:1409-1417

Rohwer S, Butcher GS (1988) Winter versus summer explanations of delayed plumage maturation in temperate passerine birds. Am Nat 131:556-572

Rutz C (2006) Home range size, habitat use, activity patterns and hunting behaviour of urban-breeding northern goshawks Accipiter gentilis. Ardea 94:185-202

Salvati L, Manganaro A, Fattorini S, Piattella E (1999) Population features of Kestrels Falco tinnunculus in urban, suburban and rural areas in central Italy. Acta Ornithol 34:53-58

Schwagmeyer PL, Mock DW (2008) Parental provisioning and offspring fitness size matters. Anim Behav 75: 291-298. doi:10.1016/j.anbehav.2007.05.023

Seress G, Bókony V, Heszberger J, Liker A (2011) Response to predation risk in urban and Rural House Sparrows. Ethology 117:896-907. doi:10.1111/j.1439-0310.2011.01944.x

Shaw LM, Chamberlain D, Evans M (2008) The House Sparrow Passer domesticus in urban areas: reviewing a possible link between post-decline distribution and human socioeconomic status. J Ornithol 149:293-299. doi:10.1007/s10336-008-0285-y

Shochat E (2004) Credit or debit? resource input changes population dynamics of city-slicker birds. Oikos 106 : 622-626. doi:10.1111/j.0030-1299.2004.13159.x

Sodhi NS, Oliphant LW (1992) Hunting ranges and habitat use and selection of urban-breeding merlins. Condor 94:743-749

Sodhi NS, Oliphant LW (1993) Prey selection by urban-breeding merlins. Auk 110:727-735

StatSoft (2013) Electronic statistics textbook. Tulsa, OK: StatSoft. WEB: http://www.statsoft.com/textbook/

Summer-Smith JD (2003) The decline of the House Sparrow in Britain: a review. Br Birds 96:439-446

Thomas RJ (2000) Strategic diel regulation of body mass in European robins. Anim Behav 59:787-791. doi:10. 1006/anbe. 1999.1360

Vangestel C, Braeckman BP, Matheve H, Lens L (2010) Constraints on home range behaviour affect nutritional condition in urban house sparrows (Passer domesticus). Biol J Linn Soc 101:41-50. doi:10.1111/j.10958312.2010.01493.x

Vedder O, Bouwhuis S, Sheldon BC (2014) The contribution of an avian top predator to selection in prey species. J Anim Ecol 83:99-106

Videler JJ (2005) Avian flight. Oxford University Press, Oxford

Vincent KE (2005) Investigating the causes of the decline of the urban House Sparrow Passer domesticus in Britain. PhD Thesis, De Montfort University, Leicester. Available from: http://www.katevincent.org

Wegrzynowicz A (2013) Changes in the House Sparrow Passer domesticus population in cities and towns of Poland in 1960-2010. Ornis Polonica 54:225-236

Witter MS, Cuthill IC (1993) The ecological costs of avian fat storage. Philos Trans R Soc Lond Ser B Biol Sci 340:73-92

Witter MS, Cuthill IC, Bonser HC (1994) Experimental investigations of mass-dependent predation risk in the European starlings Sturnus vulgaris. Anim Behav 48:201-222. doi:10.1006/anbe.1994.1227

Wojciechowska A, Dulisz B (2014) Nest site selection and density of Eurasian Magpie Pica pica in gradient of urbanization. In: Indykiewicz P, Böhner J (eds) Urban fauna. Animal, man and the city - interactions and relationships. ArtStudio, Bydgoszcz, pp. 235-248

Woods M, McDonald R, Harris S (2003) Predation of wildlife by domestic cats Felis catus in Great Britain. Mammal Rev 33:174-188. doi:10.1046/j.1365-2907.2003.00017.x 